DOI: $10.17805 /$ trudy.2020.3.8

\title{
ИССЛЕДОВАНИЕ СОСТОЯНИЯ РИТЕЙЛ СЕТЕЙ В РОССИЙСКОЙ ФЕДЕРАЦИИ
}

\author{
Е. А. Пика \\ Московский гуманитарный университет
}

\begin{abstract}
Аннотация: Розничная торговля (ритейл) является одной из крупнейших отраслей в экономике Российской Федерации. Изучение состояния ритейла позволяет оценить перспективу развития не только торговли, но и взаимосвязанных других отраслей, влияющих или зависимых от рознищы.

Текст доклада автора на Общероссийской (национальной) научной конференции «Моисеевские чтения. Культура и гуманитарные проблемы современной цивилизации», которая состоялась 4-5 марта 2020 г. в Московском гуманитарном университете
\end{abstract}

Ключевые слова: ритейл; розничная торговля; объём реализуемой продукции

\section{A RESEARCH INTO THE CONDITION OF RETAIL NETWORKS IN THE RUSSIAN FEDERATION}

\author{
E. A. Pika \\ Moscow University for the Humanities
}

\begin{abstract}
Retailing is one of the largest industries in the economy of the Russian Federation. Studying the condition of the retail industry makes it possible to estimate the prospect of development in both the retail industry and other connected industries that may influence retail or be dependent on it.

The text of the author's speech at the All-Russian (National) Scientific Conference "Moiseev's Readings. The Culture and Humanitarian Issues of Modern Civilisation", which was held at Moscow University for the Humanities on 4-5 March, 2020.
\end{abstract}

Keywords: retail; retail trade; sales volume

Розничная торговля является видом торговой деятельности, связанным с приобретением и продажей товаров для использования их в личных, семейных, домашних и иных целях, не связанных с осуществлением предпринимательской деятельности ${ }^{1}$.

В современной экономике изменения внешней среды происходят с высокой динамичностью, которая оказывает кардинальное влияние на стратегию развита тех или иных компаний торговой отрасли.

На розничную торговлю также оказывает влияние огромное количество факторов, которые в свою очередь, действуют на все предприятия в стране:

- доход потребителя;

- $\quad$ стоимость сопутствующей продукции;

- ожидания потребителя;

- конкуренция среди потребителей;

- $\quad$ величина и объём предложений на рынке.

Ритейлеры, реагируя на изменения среды, вносят корректировки в работу сети:

${ }^{1}$ Федеральный закон от 28.12.2009 № 381-Ф3 (ред. от 25.12.2018) «Об основах государственного регулирования торговой деятельности в Российской Федерации» [Электронный ресурс] // Консультант. URL http://www.consultant.ru/document/cons_doc_LAW_95629/ 
- $\quad$ переходнаотечественногопроизводителя продукциипривозникновении санкций на поставку иностранной продукции;

- перестроение логистической системы поставок, исходя из возрастания затрат на доставку продукции до торговой точки;

- по причине загруженности людей вводят новые форматы торговли, например, интернет-торговля с доставкой.

Анализ состояния ритейл сетей в России является актуальной задачей для дальнейшего прогнозирования развития сектора и понимания будущего развития других направлений связанного бизнеса.

\section{Анализ состояния ритейл сетей в России}

Россия, исходя из прогнозируемой динамики роста населения и роста доходов граждан, продолжительное время считалась перспективным направлением для иностранных компаний в сегмент розничной торговли.

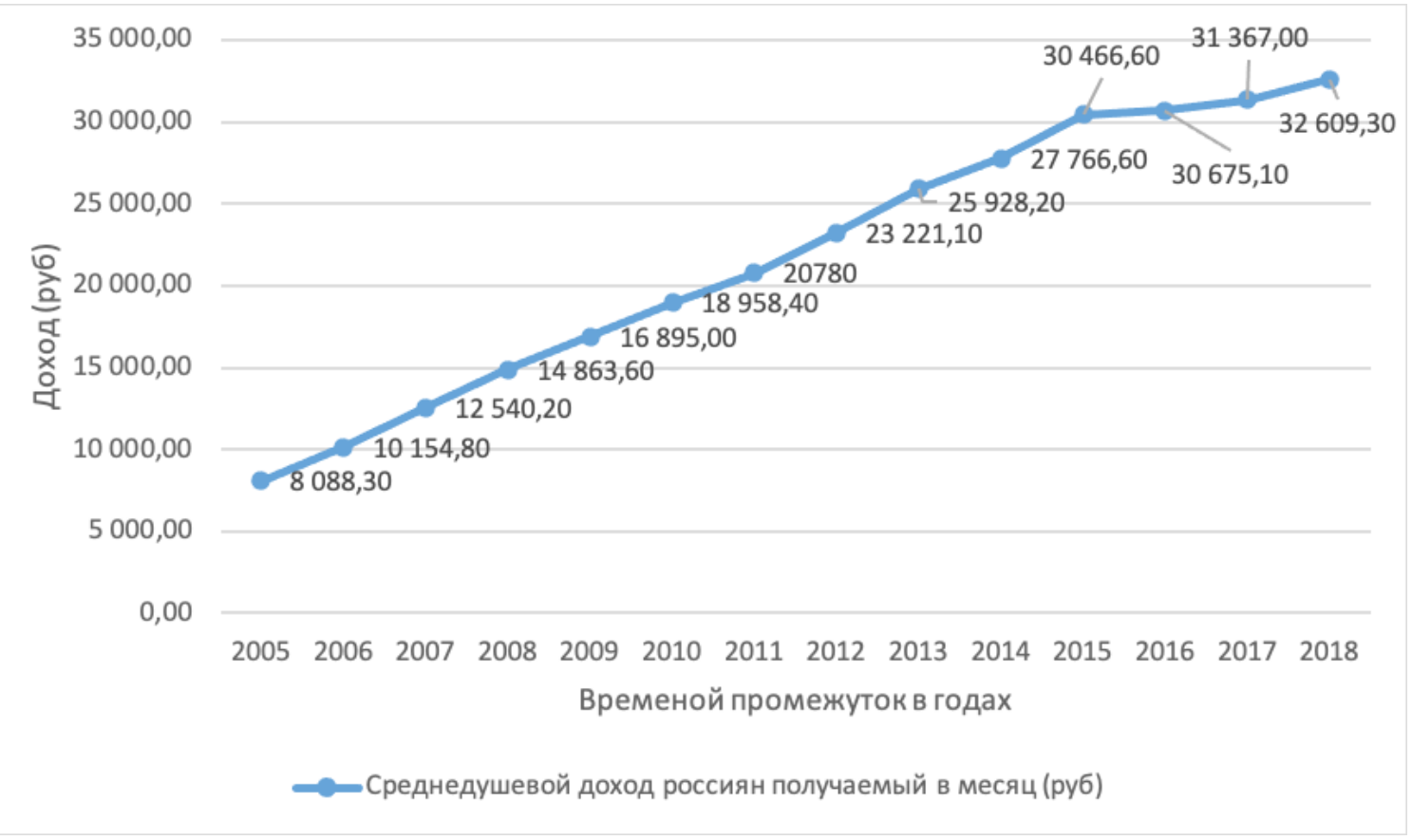

Рисунок 1. Динамика среднедушевых доходов населения по Российской Федерации, по данным Росстата. Fig. 1. The dynamics of per capita income in the Russian Federation, according to Rosstat data (Federal State Statistics Service)

Среднедушевой доход россиян, как указано на рис. 1, увеличивается.

С 2005 к 2018 г. доход увеличился в 4,03 раза: 8088,3 рублей против 32609,3 рублей соответственно. При условии прироста цен на продовольственные товары в 2006 г. - 9\%, а в 2018 г. - 4,7\%‥ Это указывает на более быстрый прирост цен, чем среднедушевой доход населения относительно инфляции.

При этом, доход по стране распределяется неравномерно. Таким образом распределение дохода между регионами может кардинально отличаться. И ритейл сети должны четко понимать, как выглядит их потребитель в том или ином регионе.

На рейтинг привлекательности регионов России для компаний оказывают влияние факторы, определяющиеся в рейтинге НРА. Данные факторы напрямую

\footnotetext{
${ }^{1}$ Инфляция на потребительском рынке [Электронный ресурс] // Официальный сайт ЦБ PФ. URL https:// cbr.ru/DKP/surveys/macro_sub/ (дата обращения: 03.02.2020).
} 
являются показателями для инвестиционных проектов и влияют на возможный риск и получаемый доход.

Среди факторов, влияющих на инвестиционную привлекательность, можно выделить следующие:

1. Географическое положение и наличие природных ресурсов: удобное месторасположение региона, количество природных ресурсов, уровень загрязнения;

2. Трудовые ресурсы. В трудовых ресурсах учитываются такие характеристики, как уровень безработицы населения, квалификация работоспособных граждан и итоговая производительность труда;

3. Развитость региональной инфраструктуры: финансовая инфраструктура региона, энергетическая, жилищная и транспортная;

4. Региональный рынок спроса: покупательская способность граждан того или иного регионального субъекта и развитость розничной торговли и рынка услуг;

5. Потенциал производства: развитость инновационной отрасли, динамика производства и размер активов региона;

6. Социально-политическая стабильность: эффективность работы законодательства с точки зрения экспертов, благоприятность налогового законодательства;

7. Финансовая устойчивость бюджета субъекта России и его предприятий: оценка финансового состояния предприятий региона, сумма налоговых поступлений.

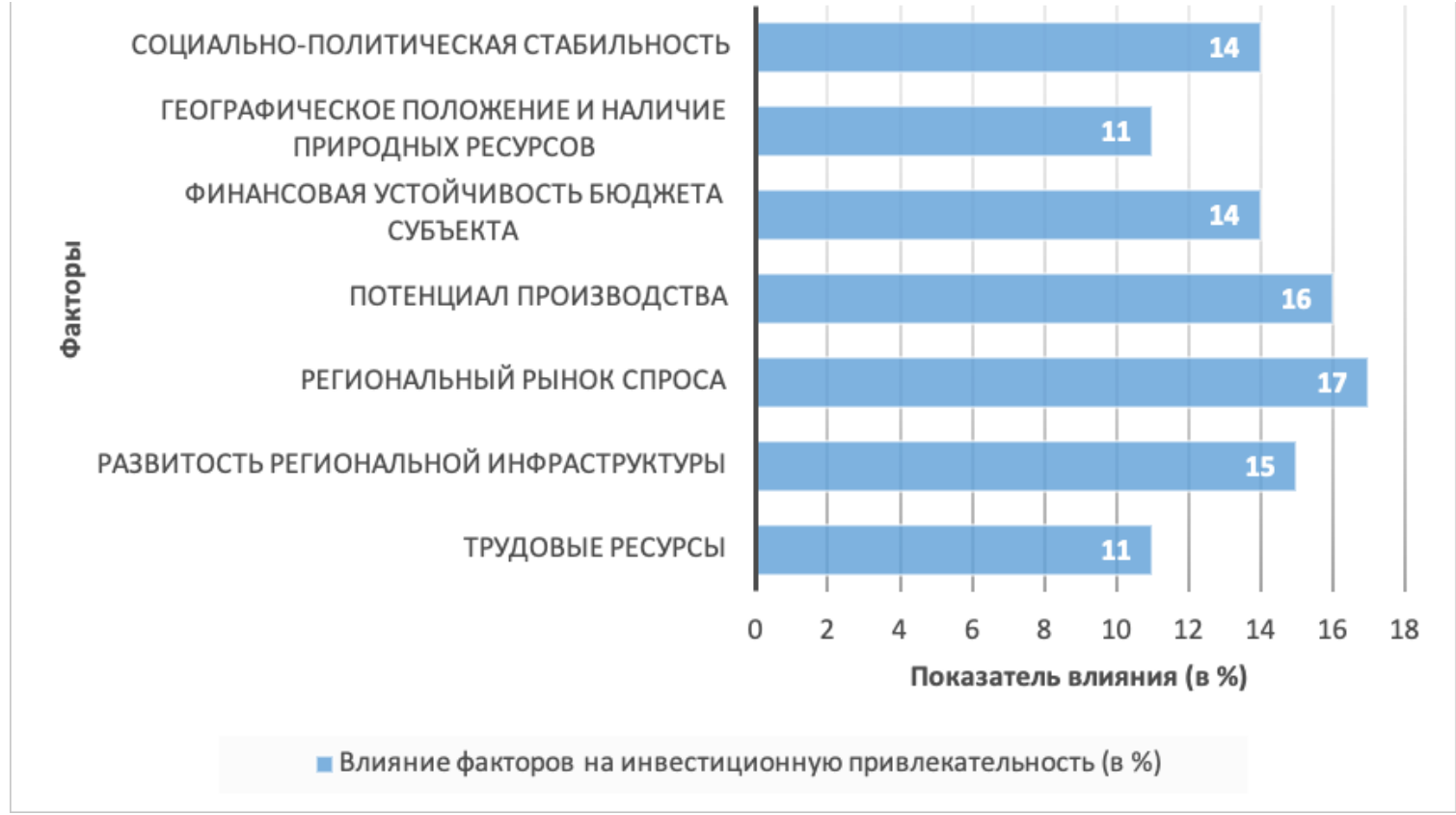

Рис. 2. Влияние факторов на инвестиционную привлекательность, в \%.

Fig. 2. The influence of various factors on investment attraction, per cent

Согласно исследованию Национального рейтингового агентства, наибольшее влияние на инвестиционную привлекательность оказывает региональный рынок спроса, а после идёт потенциал производства.

Данная особенность свидетельствует о том, что при размещение той же самой торговой точки, ритейл сеть, в первую очередь смотрит на рынок спроса, а только после на все остальное. 
Также динамика оборота розничной торговли в стране напрямую зависит от покупательской способности граждан.

Оборот розничной торговли подразумевает под собой выручку от продажи товаров населению для личного потребления или использования в домашнем хозяйстве за наличный расчет или оплаченных по кредитным карточкам, расчетным чекам банков, по перечислениям со счетов вкладчиков, по поручению физического лица без открытия счета, посредством платежных карт.

Стоимость товаров, проданных (отпущенных) отдельным категориям населения со скидкой, или полностью оплаченных органами социальной защиты, включается в оборот розничной торговли в полном объеме. В оборот розничной торговли не включается стоимость товаров, отпущенных из розничной торговой сети юридическим лицам (в т. ч. организациям социальной сферы, спецпотребителям и т. п.) и индивидуальным предпринимателям, и оборот общественного питания ${ }^{1}$.

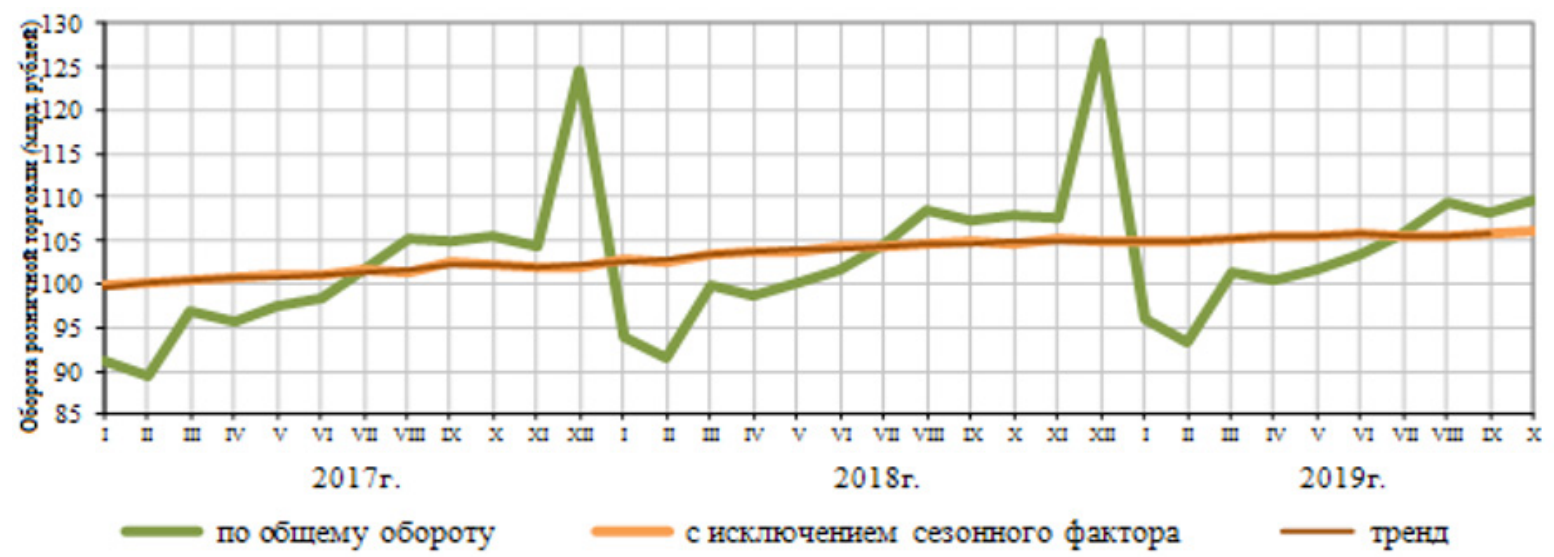

Рисунок 3. Динамика оборота розничной торговли, в млрд. рублей

Fig. 3. The dynamics of retail sales volume, in bln. roubles.

Как мы видим, динамика оборота розничной торговли показывает цикличность показателей в процентном соотношении к среднемесячному значению 2006 г. При этом, линия тренда является восходящей, что показывает устойчивый рост оборота розничной торговли, несмотря на цикличность падений.

На основе данный федеральной службы статистики РФ, структура субъектов, ведущих хозяйственную деятельность, имеет следующую картинуз:

- Состав компаний частного типа, задействованных в секторе розничной торговли, составил 290300 субъектов;

- Официально зарегистрированных граждан в качестве индивидуальных предпринимателей, занимающихся розничной торговлей, как основным видом деятельности, к концу 2018 года установилось на отметке 1258200 единиц;

\footnotetext{
${ }^{1}$ Оборот розничной торговли. Методологические пояснения [Электронный ресурс] // Федеральная служба государственной статистики. URL: https://www.gks.ru/storage/mediabank/Оборот\%20 розничной\%20торговли.html (дата обращения: 03.02.2020).

${ }^{2}$ Розничная торговля [Электронный ресурс] // Федеральная служба государственной статистики URL https://www.gks.ru/bgd/regl/b12_01/IssWWW.exe/Stg/d05/2-2-1.htm (дата обращения: 02.02.2020).

3 Розничная торговля, услуги населению, туризм [Электронный ресурс] // Федеральная служба государственной статистики. URL: http://old.gks.ru/wps/wcm/connect/rosstat_main/rosstat/ru/statistics/ enterprise/retail/\# (дата обращения: 02.02.2020).
} 

1002;

- При этом, количество розничных рынков на территории страны составило

- На территории данных рынков находится 261800 торговых мест.

\begin{tabular}{|c|c|c|c|c|c|}
\hline & \multirow[b]{2}{*}{ Bcero } & \multicolumn{2}{|c|}{ в том числе } & \multirow{2}{*}{$\begin{array}{c}\text { Оборот } \\
\text { розничной } \\
\text { торговли } \\
\text { торгующих } \\
\text { органзаций }^{1)}\end{array}$} & \multirow[b]{2}{*}{$\begin{array}{c}\text { Продажа на } \\
\text { розничных } \\
\text { рынках и } \\
\text { ярмарках }\end{array}$} \\
\hline & & $\begin{array}{l}\text { продоволь- } \\
\text { ственными } \\
\text { товарами }\end{array}$ & $\begin{array}{l}\text { непродоволь- } \\
\text { ственными } \\
\text { товарами }\end{array}$ & & \\
\hline 1992 & 5084,8 & 2324,8 & 2760,0 & 3973,8 & 1111,0 \\
\hline 1993 & 53868,8 & 23283,3 & 30585,5 & 40653,1 & 13215,7 \\
\hline 1994 & 195694,0 & 87142,1 & 108551,9 & 145132,8 & 50561,2 \\
\hline 1995 & 512025,9 & 238848,4 & 273177,5 & 376036,9 & 135989,0 \\
\hline 1996 & 728928,5 & 327278,3 & 401650,2 & 533679,6 & 195248,9 \\
\hline 1997 & 852857,4 & 391326,3 & 461531,2 & 633166,3 & 219691,1 \\
\hline 1998 & 1042799,4 & 490158,7 & 552640,6 & 771077,1 & 271722,3 \\
\hline 1999 & 1797390,0 & 866062,0 & 931328,0 & 1312725,0 & 484665,0 \\
\hline 2000 & 2352274,3 & 1093195,2 & 1259079,1 & 1735155,3 & 617119,0 \\
\hline 2001 & 3070014,0 & 1416832,3 & 1653181,7 & 2294218,0 & 775796,0 \\
\hline 2002 & 3765363,6 & 1753919,6 & 2011444,0 & 2842887,9 & 922475,7 \\
\hline 2003 & 4529632,9 & 2091747,8 & 2437885,1 & 3454648,5 & 1074984,4 \\
\hline 2004 & 5642497,7 & 2580299,2 & 3062198,5 & 4381550,9 & 1260946,8 \\
\hline 2005 & 7041509,1 & 3217647,3 & 3823861,8 & 5545798,0 & 1495711,1 \\
\hline 2006 & 8711919,9 & 3947402,3 & 4764517,6 & 7000310,4 & 1711609,5 \\
\hline 2007 & 10868976,4 & 4891343,5 & 5977632,9 & 9218579,4 & 1650397,0 \\
\hline 2008 & 13944183,1 & 6495646,2 & 7448536,9 & 12113250,1 & 1830933,0 \\
\hline 2009 & 14599153,1 & 7097079,1 & 7502074,0 & 12655449,2 & 1943703,9 \\
\hline 2010 & 16512047,0 & 8002168,2 & 8509878,8 & 14457153,8 & 2054893,2 \\
\hline 2011 & 19104336,5 & 9104324,3 & 10000012,2 & 16898443,1 & 2205893,4 \\
\hline 2012 & 21394526,2 & 9961361,5 & 11433164,7 & 19126304,5 & 2268221,7 \\
\hline 2013 & 23685913,5 & 11143008,9 & 12542904,6 & 21453829,3 & 2232084,2 \\
\hline 2014 & 26356237,3 & 12380805,5 & 13975431,8 & 24057249,0 & 2298988,3 \\
\hline 2015 & 27526793,2 & 13412264,0 & 14114529,2 & 25358189,2 & 2168604,0 \\
\hline $2016^{4 !}$ & 28240884,9 & 13716580,0 & 14524304,9 & 26298361,0 & 1942523,9 \\
\hline $2017^{41}$ & 29745535,5 & 14402840,9 & 15342694,6 & 27879584,6 & 1865950,9 \\
\hline 2018 & 31579371,8 & 15055431,1 & 16523940,7 & 29799468,9 & 1779902,9 \\
\hline
\end{tabular}

Рисунок 4. Оборот розничной торговли в Российской Федерации ${ }^{1}$

Fig. 4. Retail turnover in the Russian Federation

Мы можем наблюдать в таблице оборот розничных рынков и ярмарок к 2018 году снижается. При этом, идёт увеличение оборота розничных торговых организаций. Данные аспекты свидетельствуют о снижении количества рынков и ярмарок. Но при характерном снижении рынков происходит увеличение сетевых торговых предприятий.

Сетевые торговые предприятия вытесняют мелкие несетевые розничные магазины, такие как магазины у дома, за счёт определенных параметров:

- Снижения цены за счёт объемов продаж сети;

- Внедрения качественных стандартов обслуживания;

- Построения логистической системы, позволяющей с относительно наименьшими затратами доставить товар в отдаленные концы страны;

1 Розничная торговля. Классификация предприятий: Гост $\mathrm{P} \quad 51773-2001$ [Электронный ресурс] // Консультант. URL: http://www.consultant.ru/cons/cgi/online.cgi?req=doc\&base=0TN \&n=9922\#002991885968266539 (дата обращения: 02.02.2020). 
- Внедрения электронной системы, следящей за оборотом продукции, позволяющей оперативно оценить изменения спроса на товар.

Потребители, действительно, сейчас стали обращать внимание не только на стоимость продукции, но и на сервис, оказываемый в магазинах. Порой, репутация магазина играет ключевую роль для принятия решения о покупке.

В данный период времени, с учётом ускорения темпа жизни, многие переходят к покупкам через интернет. Поэтому производители и торговые предприятия стараются охватить и данное направление.

Во многом помогают решить вопрос с размещением продукции в интернете площадки - маркетплейсы: Ozon, Amazon, Яндекс.Маркет, Беру.

Интернет-площадки берут на себя рекламу товара и его продвижение. Многим небольшим магазинам, реализующим собственную продукцию, наиболее выгоден формат торговли через маркетплейс по нескольким причинам:

- Маркетплейс уже проанализировал аудиторию, купившую товар клиента и может предложить статистические данные для анализа;

- Настройка рекламы происходит на самой площадки. А сами затраты на рекламу начинают вычитаться с баланса проданной продукции на портале;

- Не нужно платить за размещение товара и дополнительную комиссию, кроме комиссии за реализованный товар;

- Маркетплейс берет на себя доставку товара до конечного потребителя.

Подводя итог, необходимо выделить основные характеристики состоянии ритейл сетей:

1. Ритейл сети вытесняют мелкие магазины;

2. Покупатели отдают наибольшее предпочтение сервису, предлагаемому в сетевых магазинах;

3. Розничные магазины переходят в интернет формат для того, чтобы быть ближе к целевому потребителю;

4. Ритейл сети, в период санкций, стали более ориентированы на отечественного производителя.

Как было сказано ранее, розничная торговля, как и весь бизнес, подвержены изменениям в связи изменениями внешней среды. Оперативная реакция на изменения позволяет не только увеличить доходность предприятия, но и, как минимум, удержаться на плаву в периоды кризиса.

Дата поступления: 20.03.2020 2.

Пика Егор Александрович - студент магистратуры Московского гуманитарного университета. Адрес: 111395, Россия, г. Москва, ул. Юности, д. 5. Тел.: +7 (926) 838-67-06. Эл. адрес: egor-pika@yandex.ru

Pika Egor Aleksandrovich, Graduate Student, Moscow University for the Humanities. Postal address: 5, Yunosti St., Moscow, Russian Federation, 111395. Tel.: +7 (926) 838-6706. E-mail: egor-pika@yandex.ru

\section{Для цитирования:}

Пика Е. А. Исследование состояния ритейл сетей в Российской Федерации // Научные труды Московского гуманитарного университета. 2020. №3. C. 42-47. DOI: https://www.doi. org/10.17805/trudy.2020.3.8 